\title{
An assessment on oil spill trajectory prediction: Case study on oil spill off Ennore Port
}

\author{
S J Prasad ${ }^{1,2, *}$, T M BALAKRishnan NAIR ${ }^{1}$, HASibur RAHAMAN ${ }^{1}$, \\ S S C ShENOI ${ }^{1}$ and T ViJAYALAKSHMI ${ }^{2}$ \\ ${ }^{1}$ ESSO - Indian National Centre for Ocean Information Services, Hyderabad 500 090, India. \\ ${ }^{2}$ Jawaharlal Nehru Technological University, Hyderabad, Telangana 500 085, India. \\ *Corresponding author.e-mail: prasadsj@incois.gov.in
}

MS received 24 October 2017; revised 12 February 2018; accepted 12 February 2018; published online 29 September 2018

A Liquefied Petroleum Gas (LPG) tanker and a chemical tanker collided two nautical miles off Ennore port on 28 January, 2017. Around 196.4 metric tons (MT) of Heavy Furnace Oil (HFO) was spilled and drifted towards the shore. Oil spill drift advisory and prediction was made by Indian National Centre for Ocean Information Services (INCOIS) using General National Oceanic and Atmospheric Administration (NOAA) Operational Modeling Environment (GNOME), an oil spill trajectory model. The trajectory model was forced with analysed and forecasted ocean currents from Global Ocean Data Assimilation System (GODAS) based on Modular Ocean Model 4p1 (GM4p1). It was found that spread of HFO obtained from oil spill trajectory model GNOME, has matched well with the observed spread from Sentinel-1A satellite dataset. However, the spread of the HFO was underestimated by the trajectory model, when forced with forecasted GM4p1 currents. Additional ground truth observation from Indian Coast Guard also corroborates this finding.

Keywords. Ennore; oil spill; trajectory; radar; fronts; GNOME.

\section{Introduction}

On 28 January, 2017, 0345 hrs, Indian Standard Time (IST), BW Maple, an outbound Liquefied Petroleum Gas (LPG) tanker and an inbound chemical tanker MT Dawn Kanchipuram, collided about two nautical miles $\left(13.2282^{\circ} \mathrm{N}, 80.3633^{\circ} \mathrm{E}\right)$ off Kamarajar Port, Ennore. According to local port authority, the hull of the vessel MT Dawn was ripped, damaging the ship's accommodation as well as the pipelines on the deck. As per the information from Indian Coast Guard, East, this accident has resulted in the spillage of 196.4 metric tons of Heavy Furnace Oil (HFO). The HFO spill location is shown in figure 1 . The nowcast and predictions were made for the drift of $\mathrm{HFO}$, using an oil spill trajectory model, General National Oceanic and Atmospheric Administration (NOAA) Operational Modeling Environment (GNOME). The simulated and observed drift of HFO are compared and presented in this paper.

\subsection{Request from the Indian Coast Guard}

Indian Coast Guard (ICG), Ministry of Defence, is responsible for the clean up and mitigation of the damages due to the oil spill in Indian coastal waters. A specific request came from Indian Coast Guard, Chennai, to INCOIS for providing the advisory, on the drift of spilt HFO in nowcast and 


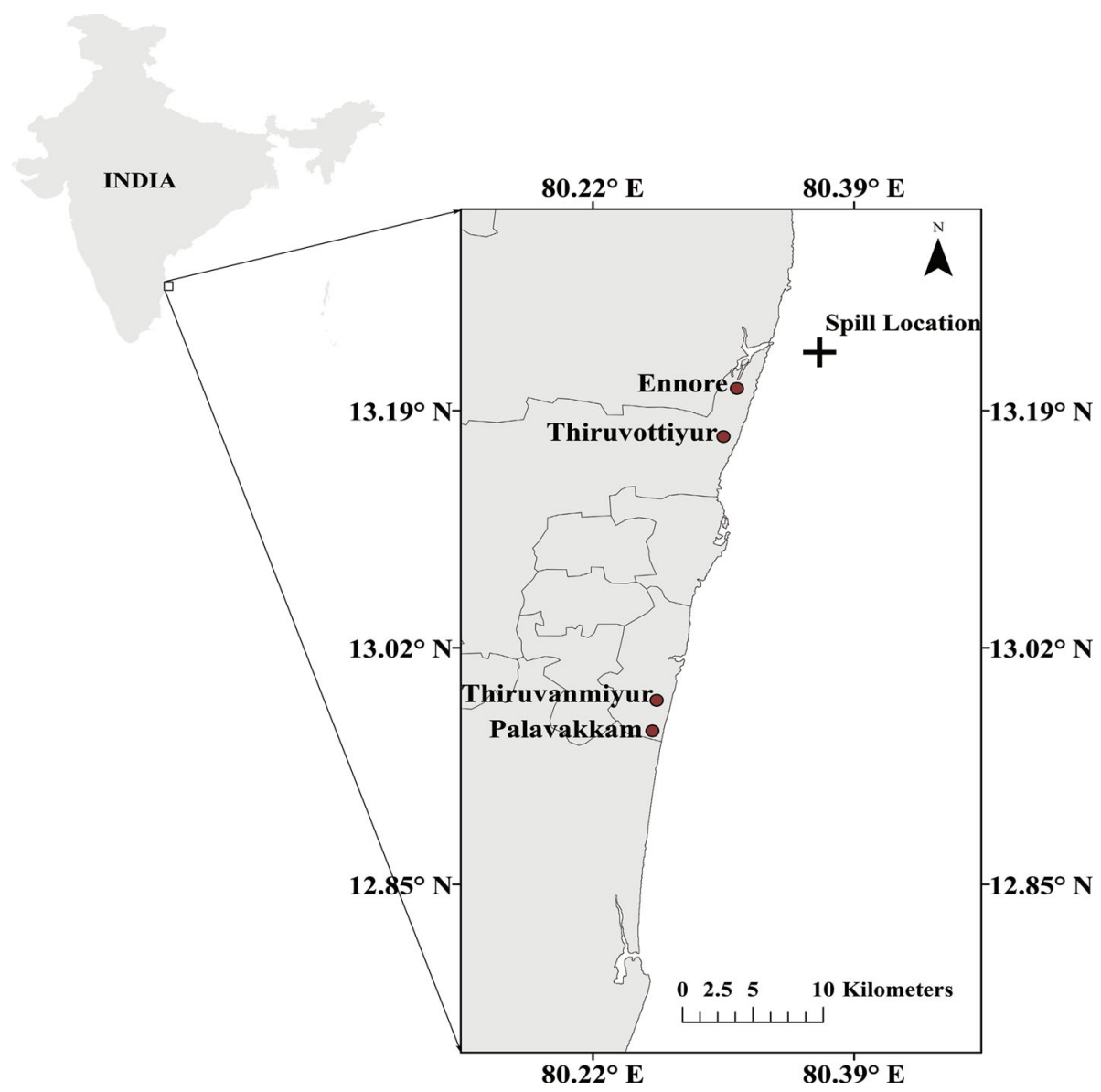

Figure 1. Map of India along with HFO spill location near Ennore port at the east coast of India. Zoomed version of the HFO spill location is also shown in the rectangular box.

forecast modes. As per ICG's request the trajectory prediction model was run with ICG's initial estimated 20 metric tons of $\mathrm{HFO}$ and the advisories were disseminated as bulletins for their clean-up operations commenced after 28 January, 2017 on near real time. The change in the quantity of the HFO due to clean up operations was not considered in modeling the drift. ICG after detailed analysis reported that the actual quantity of HFO spillage was 196.4 MT. Then, to make an objective assessment, the model was re-run with this actual quantity (196.4 MT) during 0400 hrs of 28 January, 2017 to 2300 hrs of 5 February, 2017 to estimate the drift of spilled HFO.

\subsection{Oil spill trajectory prediction setup at INCOIS}

Indian National Centre for Ocean Information Services (INCOIS), Hyderabad developed a numerical modeling setup to predict the trajectory of the spilled HFO, based on prevailing, forecasted winds, currents and waves in the region of spill. The core model is GNOME, an oil spill trajectory model developed by NOAA (Beegle Krause 2001). This model was adopted from NOAA and operated at INCOIS by customizing it in diagnostic mode for Indian ocean. The diagnostic mode allows the user to set his own scenario (Beegle Krause 2001). The model estimates the movement of oil spill as the vector sum of wind speed, current speed and diffusion turbulence. The resultant of these forcings at each and every time step gives the impetus for the oil to drift. GNOME uses three phased algorithm, in which the pollutant is treated as three component substances with independent half lives (Zelenke et al. 2012). Prasad et al. (2014) explained the detailed methodology adopted for predicting the trajectory of spilled oil and its validation for Mumbai oil spills. In the present study, the wind drift was obtained from the forecasted wind fields of European Centre for Medium Weather Range Forecast (ECMWF). The ECMWF winds were validated with in-situ data obtained from the Automatic Weather Stations (AWS) installed on board ships. The root mean square error was found to be $<2.6 \mathrm{~m} \mathrm{~s}^{-1}$ (Harikumar et al. 2012). As per 
the trajectory analysis handbook of NOAA, $3 \%$ of wind speed is considered for the drift of the pollutant parcel (http://response.restoration.noaa.gov/ sites/default/files/Trajectory_Analysis_Handbook. pdf). The diffusion turbulence is based on the horizontal eddy diffusivity of ocean water and value of $100,000 \mathrm{~cm}^{2} \mathrm{~s}^{-1}$ (Zelenke et al. 2012) was used by the present GNOME trajectory model. In the present study, we have used ocean surface currents from a global assimilation system. Global Ocean Data Assimilation System (GODAS) based on MOM4p0d adopted from NOAA/National Centers for Environmental Prediction (NCEP) and operated at INCOIS in 2013. This system uses state of the art ocean general circulation model called Modular Ocean Model (MOM) version-4p0d and 3D-VAR assimilation technique to assimilate in-situ data in the model. Temperature and salinity profiles from all in-situ observations over the global ocean are assimilated to produce the best analysis products (Ravichandran et al. 2013; Sivareddy et al. 2015). Recently, Rahaman et al. (2015) upgraded the GODAS with MOM4p1 and have further improved the ocean analysis with this upgraded version. We used this upgraded GODAS analysed and forecasted surface currents. Hereafter, the GODAS based MOM4p1 version will be referred as GM4p1.

\section{The simulations of trajectory prediction model}

The simulations of the trajectory model, GNOME, was made with 196.4 MT of HFO. The trajectory model was forced with analysed forcing fields of GM4p1 on daily basis until 2300 hrs of 1 February, 2017. Figure 2 shows the nowcasted status (floating as blue dots and beached as black $\times$ symbols) of the spilled HFO from $0400 \mathrm{hrs}$ of 28 January, 2017 to $2300 \mathrm{hrs}$ of 1 February, 2017. It can be seen that $\sim 6 \mathrm{~km}$ of coastal stretch was affected due to the HFO drift on 1400 hrs of 28 January, 2017 (figure 2a). This affected area further extended towards south up to $\sim 18 \mathrm{~km}$ along the coast on $2300 \mathrm{hrs}$ of 29 January, 2017 (figure 2b). In the next two days, the HFO spread further south and reached near Thiruvanmiyur and Palavakkam (figure $2 \mathrm{c}$ and $\mathrm{d}$ ). Afterwards, the trajectory model was run with forecasted GM4p1 currents from 0000 hrs of 2 February, 2017 to 2300 hrs of 5 February, 2017, for which the forecast was issued from our laboratory on $0000 \mathrm{hrs}$ of 2 February, 2017.
Figure 3 shows the predicted status (floating as red dots and beached as black $\times$ symbols) of the spilled HFO from 0000 hrs of 2 February, 2017 to 2300 hrs of 5 February, 2017. It can be seen from figure 3 that, HFO will drift further south of Palavakkam during 2300 hrs of 2 February, 2017 to 2300 hrs of 5 February, 2017. Further, ICG has reported the remnants of HFO at various coastal locations such as Ennore, Thiruvottiyur, Thiruvanmiyur and Palavakkam on 5 February, 2017. These locations were very much within the predicted area over which the oil spill will move. Further, we have evaluated the nowcasted and forecasted HFO spread with the independent satellite observation.

\section{Synthetic Aperture Radar (SAR) data used for validating HFO spread}

The available VV (vertical-vertical) polarized data from space borne Synthetic Aperture Radar (SAR) sensor was obtained for the pass that occurred over Ennore region at 0600 hours (IST) on 29 January, 2017 from Sentinel-1A data hub (https://scihub. esa.int/dhus/). This data was processed using Sentinel tool box to identify the signature of oil spill. The radar reflectance values are converted to dimensionless normalized Sigma0 intensity values in Sentinel tool box. This Sigma0 values were wrote in netcdf format for identifying the oil slicks. Figure 4(a) shows radar reflectance from the SAR sensor. The intensity values are plotted in logarithmic scale. The low back scatter values are shown as dark blue and high values are in dark red. As per our knowledge, there is no objective criteria available to identify HFO based on radar reflectance values. However, typically the presence of oil shows low reflectance values over ocean water. In order to identify the extent of HFO spread near to Ennore we have used radar reflectance values of $-2.4(\log 0.004)$. This value was used based on the in-situ observations of ICG. The pixels with intensity values $\leq-2.4(\leq \log 0.004)$, corresponds to the ICG reported locations (Ennore, Thiruvottiyur) of beached HFO slicks on 29 January, 2017. Hence they are considered as HFO slicks. However, all the pixels with values less than -2.4 do not correspond to HFO. The lower back scatter values can also be associated with the oceanic fronts (Lyzenga et al. 2004; Lorenzzetti et al. 2008). de Macedo and Lorenzzetti (2015) noticed the ocean fronts in Multiscale Ultra High Resolution (MUR) Sea Surface Temperature (SST) data which reflected 

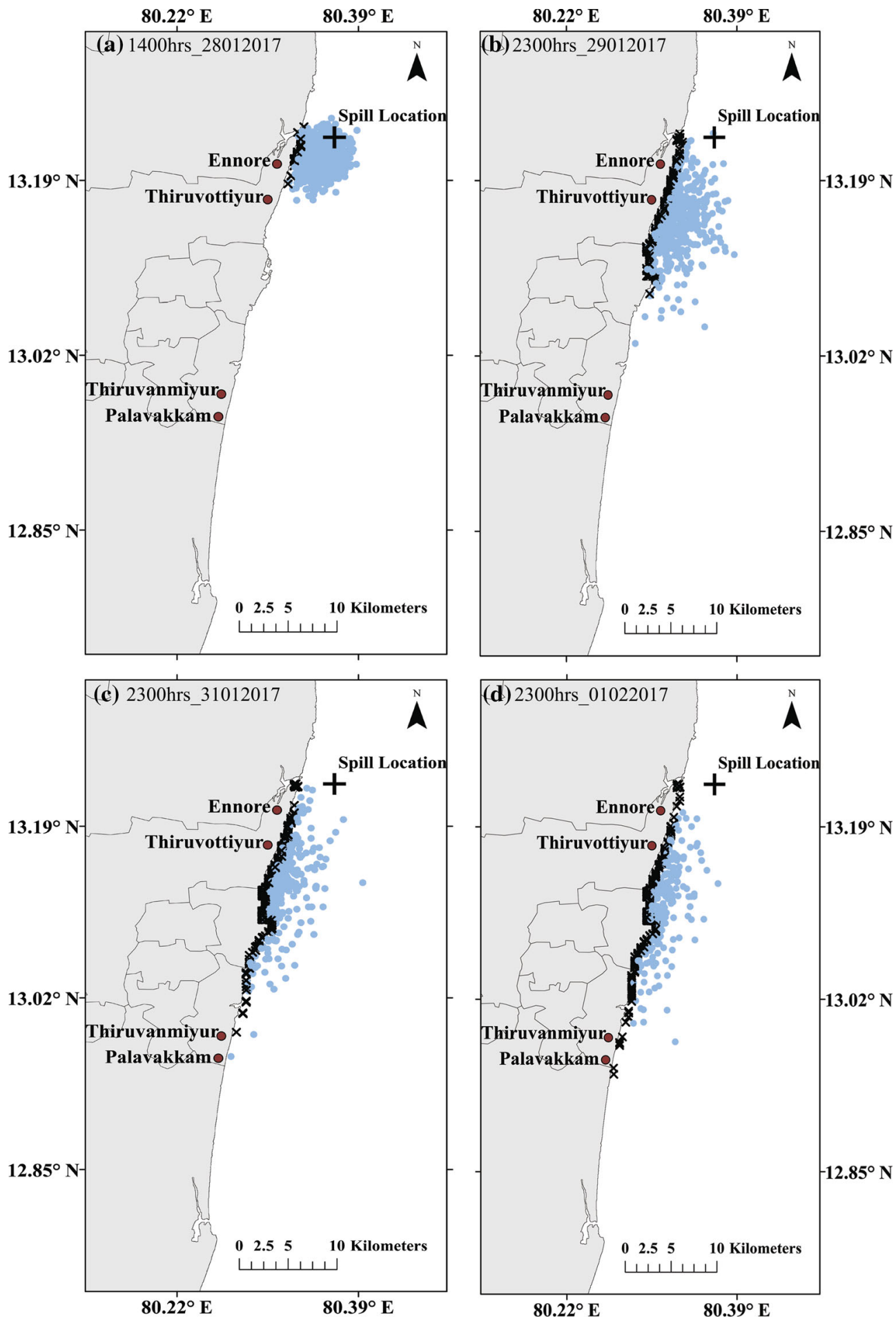

Figure 2. Nowcasted HFO drift using analyzed GM4p1 currents. The black $\times$ (blue dot) denotes the beached (floating) status of drifted HFO in all the panels (a) spread of HFO on 1400 hrs of 28 January, 2017, (b) spread of HFO on 2300 hrs of 29 January, 2017, (c) spread of HFO on 2300 hrs of 31 January, 2017, and (d) spread of HFO on 2300 hrs of 1 February, 2017.

in Envisat datasets obtained on 15 October, 2009. Hence, we have analyzed the $1 \mathrm{~km}$ resolution SST data, from Group of High Resolution Sea Surface Temperature (GHRSST; https://www.ghrsst.org/ ghrsst-data-services/products/) to see whether any oceanic front exists in that area. Since we could not acquire the concurrent SST data exactly during acquisition of SAR data, we have analysed the daily averaged SST data obtained on 29 January, 2017 to delineate the fronts present in the region. 

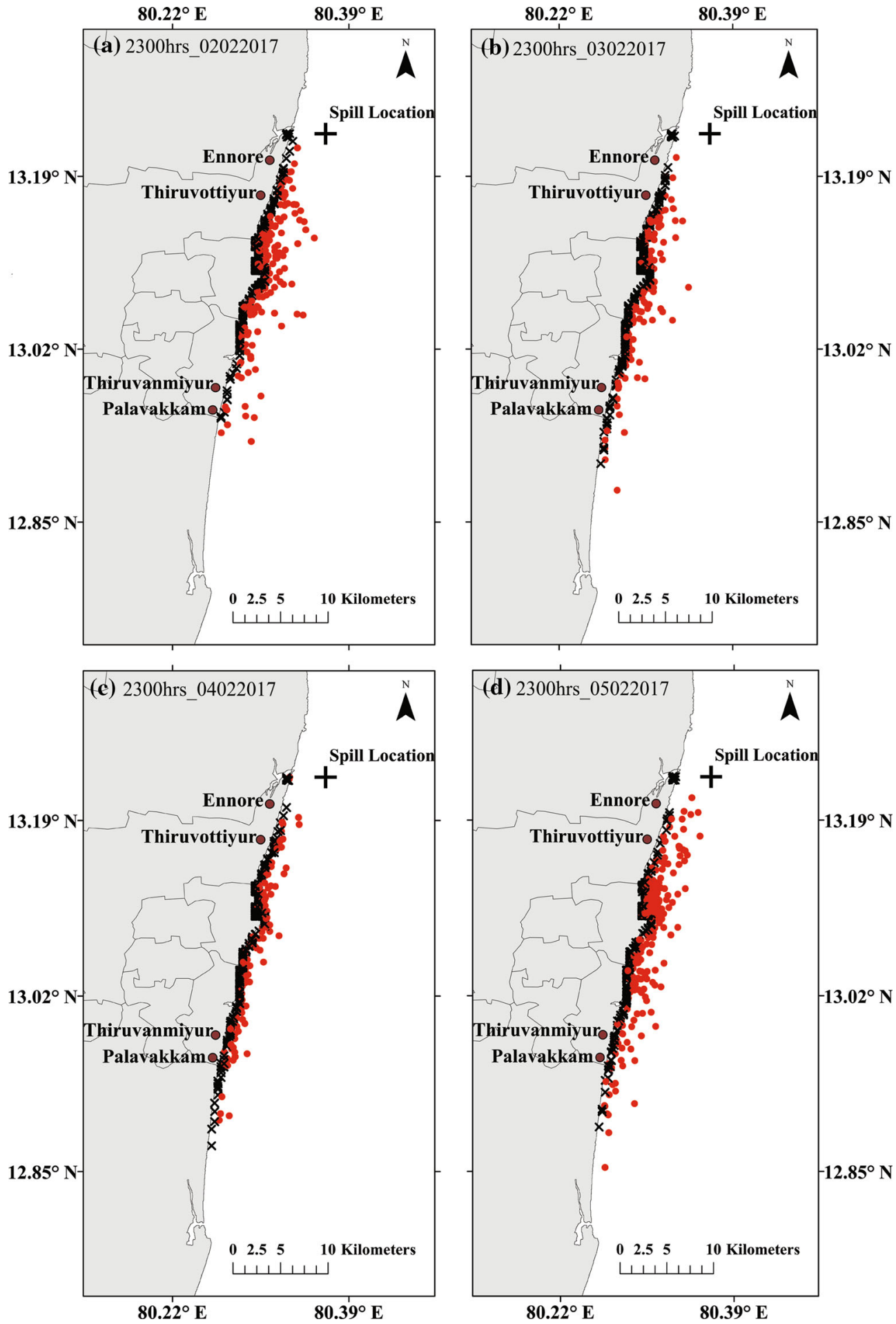

Figure 3. Forecasted HFO drift using forecasted GM4p1 currents. The black $\times$ (red dot) denotes the beached (floating) status of drifted HFO in all the panels (a) spread of HFO on 2300 hrs of 2 February, 2017, (b) spread of HFO on 2300 hrs of 3 February, 2017, (c) spread of HFO on 2300 hrs of 4 February, 2017, and (d) spread of HFO on 2300 hrs of 5 February, 2017.

Figure 4(b) shows the spatial distribution of daily averaged SST on 29 January, 2017. The presence of prominent fronts can be seen, that corresponds to low radar reflectance values in figure 4(a). To delineate the spread of HFO, the areas covered by fronts were then excluded from the SAR data. Finally, the HFO's spread is identified and marked with the black contour in figure $4(\mathrm{a})$. The SAR data shows that $\sim 15 \mathrm{~km}$ of the coastline was affected by the HFO at $0600 \mathrm{hrs}$ on 29 January, 2017 and 

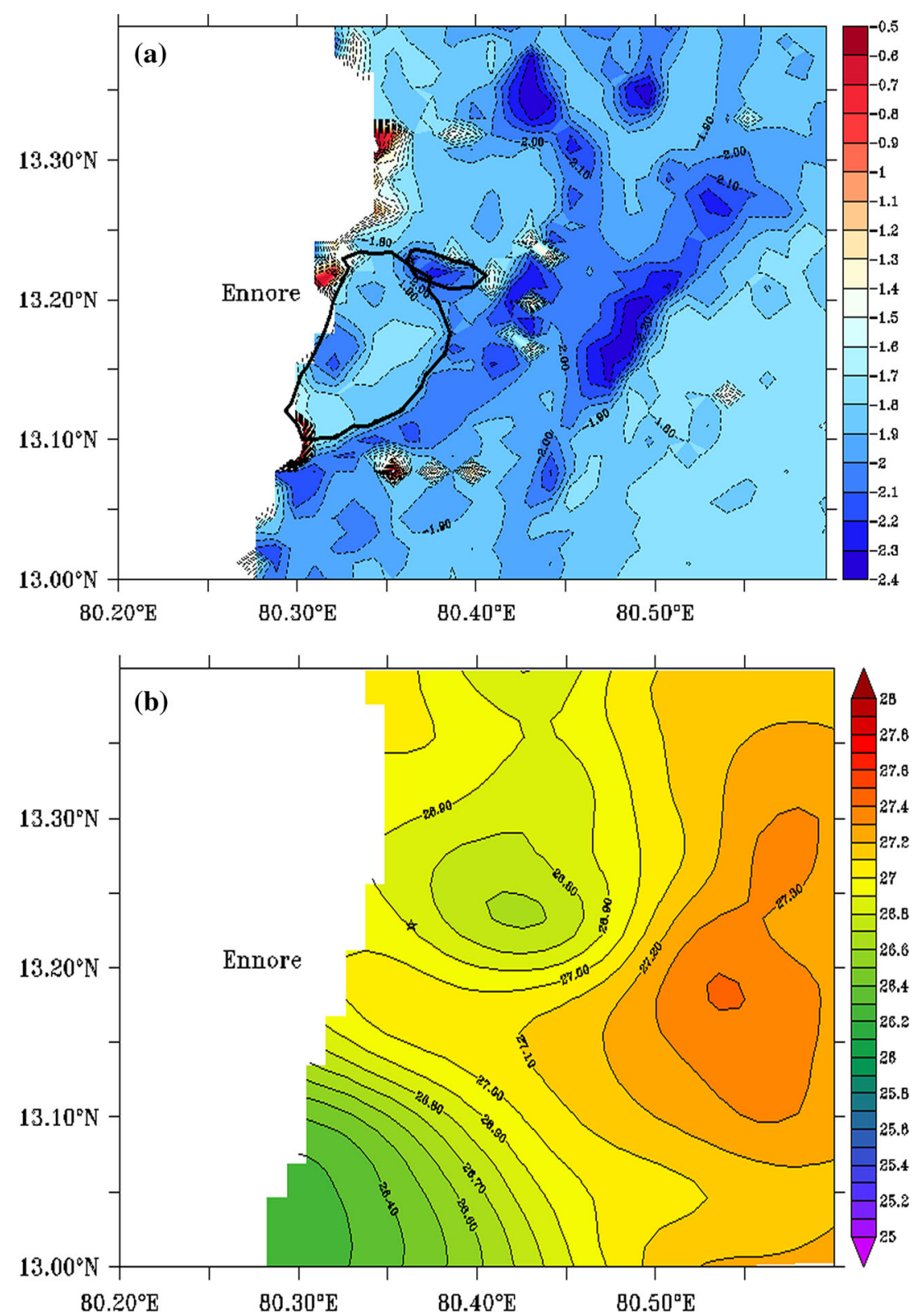

Figure 4. (a) Logarithmic plot of radar reflectance from Sentinel-1A satellite observation on 0600 hrs of 29 January, 2017. The black contour line shows the HFO spread zone. (b) Daily averaged Sea Surface Temperature (SST in $\left.{ }^{\circ} \mathrm{C}\right)$ on 29 January, 2017 from GHRSST observation.

the area affected by the oil spill works out to be $\sim 105 \mathrm{~km}^{2}$.

\section{Comparison of model nowcast/forecast with satellite observations}

The comparison between the trajectory obtained from analysed/forecasted GM4p1 currents and the observed oil spill signature from SAR data is shown in figure 5. The comparison was made at the time of SAR acquisition, that is at 0600 hours on 29 January, 2017. The forecast on ocean currents issued from our laboratory on $0800 \mathrm{hrs}$ of 27 January, 2017, was used for the comparison. The observed spread zone of HFO exported from SAR data is shown as black contour in figure 5(a). The spread of HFO based on analysed and forecasted currents are shown as blue and red dots, respectively. The beached status of HFO on 0600 hrs of 29 January, 2017 are indicated as black $\times$ symbols. It can be seen that the offshore and the alongshore spread of HFO estimated using the analysed fields of currents compares better with the observations using SAR, than the trajectory predicted with the forecasted currents. The predicted spill spread captured the 

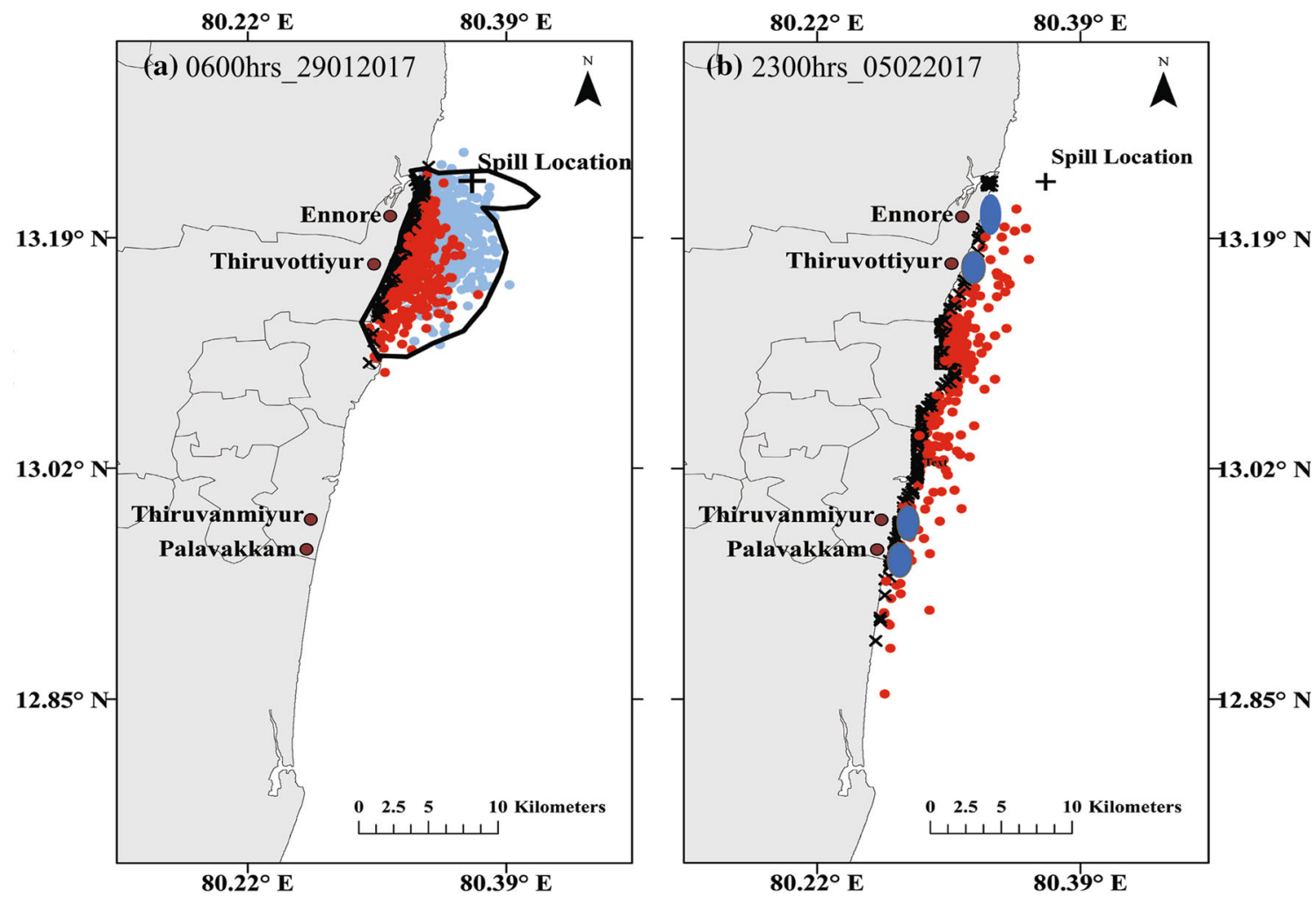

Figure 5. (a) Comparison of HFO drift obtained from analyzed and forecasted currents on 0600 hrs of 29 January, 2017 with satellite observation. The black contour line indicates the observed HFO spread zone obtained from SAR dataset. The blue (red) dots indicate the spread of HFO obtained from analyzed (forecasted) GM4p1 currents. The black $\times$ denotes the beached status of the HFO. (b) Comparison of predicted HFO drift on 2300 hrs of 5 February, 2017 with the in-situ observation. The black $\times$ (red dot) denotes the beached (floating) status of HFO obtained from forecasted GM4p1 currents. The blue ellipses are the coastal locations where ICG reported the presence of HFO on 5 February, 2017.

alongshore spread of HFO, but did not capture the offshore spread. This is not surprising, considering the higher accuracies of analysed fields compared to the forecasted fields in any model. Figure 5(b) shows the plot of comparison between the predicted and in-situ observed drift of HFO on 5 February, 2017. The predicted drift of HFO using forecasted GM4p1 is indicated as red dots (floating) and black $\times$ symbols (beached). The blue ellipses are the coastal locations where ICG reported the presence of HFO. It can be seen that the predicted spread matches very well with the observed HFO.

\section{Conclusions}

An oil spill occurred off Ennore port, Chennai on 28 January, 2017 due to the collision of two merchant vessels. Advisories on the drift and spread of 20 MT HFO were issued, to the Indian Coast Guard on nowcast and forecast basis during 28 January, 2017 to 5 February, 2017. This advisory was based on a trajectory model GNOME.
In-order to make an objective assessment, the simulations were updated with the actual spill quantity of HFO (196.4 MT). Upgraded GODAS analysed/forecasted currents and ECMWF winds are used to force the trajectory model. The simulated trajectories match well with SAR and ICG in-situ observations. The observed along and off shore spread of the slicks were well captured by the GNOME when forced with analysed GM4p1 currents. The offshore spread was slightly underestimated while using forecasted GM4p1 currents.

\section{Acknowledgements}

The authors thank the officials of Indian Coast Guard, Chennai for their information on oil spill and support in validating the trajectory predictions of spilled HFO. Authors acknowledge that the executable of oil spill model GNOME is adopted from NOAA and set up in diagnostic mode for simulating oil spill trajectories of Indian Ocean scenario. Thanks are due to the developers of 
NOAA GNOME. ArcMap tool was used to plot and generate the trajectory output in native EPS format. Ferret software in Linux environment was used to interpret the SAR data. The authors thank the editor and reviewers for their comments and suggestions in improving the manuscript's quality. This research paper holds the INCOIS contribution number 314 .

\section{References}

Beegle Krause J 2001 General NOAA Oil Modeling Environment (GNOME): A new spill trajectory model; Proc. Int. Oil Spill Conf. 2 865-871.

de Macedo C R and Lorenzzetti J A 2015 Numerical simulations of SAR microwave imaging of the Brazil current surface front; Braz. J. Oceanogr. 63(4) 481-496, https:// doi.org/10.1590/S1679-87592015082306304.

Harikumar R, Balakrishnan Nair T M, Bhat G S, Nayak S, Venkat Shesu Reddem and Shenoi S S C 2012 Shipmounted real-time surface observational system on board Indian vessels for validation and refinement of model forcing fields; J. Atmos. Oceanic. Technol. 30 626-637.

Lorenzzetti J A, Kampel M, Franca B and Sartori A 2008 An assessment of the usefulness of SAR images to help better locating the Brazil Current surface inshore front; In: International Workshop on Advances of SAR oceanography from Envisat and ERS Missions, Frascati Proceedings, European Space Agency, 42p.

Lyzenga D R, Marmorino G O and Johannessen J A 2004 Ocean currents and current gradients; In: Synthetic Aperture Radar Marine User's Manual (eds) Jackson C R and Apel J R, Washington, NOAA, pp. 207-220.

Prasad S J, Balakrishnan Nair T M, Francis P A and Vijayalaksmi T 2014 Hindcasting and validation of Mumbai oil spills using GNOME; Int. Res. J. Environ. Sci. 12 3-12.

Rahaman H, Behringer D W, Penny S G and Ravichandran M 2015 Impact of an upgraded model in the NCEP global ocean data assimilation system: The tropical Indian Ocean, J. Geophys. Res. Oceans. https://doi.org/10.1002/ 2016JC012056.

Ravichandran M, Behringer D, Sivareddy S, Girishkumar M S, Chacko N and Harikumar R 2013 Evaluation of the global ocean data assimilation system at INCOIS: The tropical Indian Ocean; Ocean Model. 69 123-135, https:// doi.org/10.1016/j.oceamod.2013.05.003.

Sivareddy S, Ravichandran M, Sivasankaran G M and Rama Prasad K V S 2015 Assessing the impact of various wind forcing on INCOIS-GODAS simulated ocean currents in the equatorial Indian Ocean; Ocean Dyn. 65(9) 12351247, https://doi.org/10.1007/s10236-015-0870-6.

Zelenke B, Connor C O, Barker C, Beegle-Krause J and Eclipse L 2012 General NOAA Operational Modeling Environment (GNOME) Technical Documentation; U.S. Dept. of Commerce, NOAA Technical Memorandum NOS OR\&R 40, Seattle, WA, Emergency Response Division, NOAA, 105p. 